\title{
Spatial pattern in species richness of demersal fish assemblages on the continental shelf of the northern Mediterranean Sea: a multiscale analysis
}

\author{
Jean-Claude Gaertner ${ }^{1, *}$, Jacques A. Bertrand ${ }^{2}$, Giulio Relini ${ }^{3}$, \\ Costas Papaconstantinou ${ }^{4}$, Nabila Mazouni ${ }^{5}$, Luis Gil de Sola ${ }^{6}$, Jean-Pierre Durbec ${ }^{1}$, \\ Stjepan Jukic-Peladic $^{7}$, Arnauld Souplet ${ }^{8}$ \\ ${ }^{1}$ Centre d'Océanologie de Marseille, LMGEM, UMR CNRS 6117, Rue de la batterie des Lions, 13007 Marseille, France \\ ${ }^{2}$ IFREMER, Laboratoire Ecologie Halieutique, BP 21105, 44311 Nantes Cedex 03, France \\ ${ }^{3}$ Universita di Genova, Via Baldi 5, 16126 Genoa, Italy \\ ${ }^{4}$ NCMR, Aghios Kosmas Hellinikion, 16644 Athens, Greece \\ ${ }^{5}$ Cépralmar, 20 rue de la République, 34000 Montpellier, France \\ ${ }^{6}$ Centro Oceanográphico de Málaga (IEO), Puerto pesquero s/n, 29640 Fuengirola (Malaga), Spain \\ ${ }^{7}$ Institut Za Oceanografiju i Ribarstvo, PO Box 500, 21000 Split, Croatia \\ ${ }^{8}$ IFREMER, Laboratoire Ressources Halieutiques, BP 171, 34203 Sète, France
}

\begin{abstract}
The species richness pattern of groundfish species in the entire northern Mediterranean Sea was examined at 3 spatial scales: region, large biogeographical zone and basin. We analysed 1914 trawl hauls collected using a single sampling design in the trawlable areas of the continental shelves between the Strait of Gibraltar and the Strait of Dardanelles (from 36.3 to $45.7^{\circ} \mathrm{N}$ and $5.3^{\circ} \mathrm{W}$ to $28^{\circ} \mathrm{E}$ ). Spatial pattern in species diversity was assessed using complementary methods (Chao2 estimates of total species richness, mean species richness and beta diversity). No matter which scale was used, the expected longitudinally decreasing trend in species richness, which has been widely described in previous studies, did not appear when comparing estimates of total species richness per unit of area. Only the mean species richness pattern showed a moderate eastwards decrease at the largest spatial scale, but the trend progressively disappeared as the scale of analysis was reduced. In contrast to what is usually expected, our results suggest that Atlantic inflow does not play a key role in the present spatial pattern of fish species richness within the northern Mediterranean Sea. Furthermore, we show that the Aegean Sea can no longer be considered the least species-diverse zone in the northern Mediterranean Sea. Our results provide the first description of a quantitative 'reference state', with which the temporal changes in species richness patterns throughout the entire northern Mediterranean Sea can be compared in the future.
\end{abstract}

KEY WORDS: Species richness · Beta diversity · Groundfishes · Mediterranean Sea $\cdot$ Large scale · Lessepsian

Resale or republication not permitted without written consent of the publisher

\section{INTRODUCTION}

Species diversity is of increasing concern in ecology and conservation biology. Following numerous investigations at local and regional scales in recent years, there is now a growing demand for both large and multiscale analyses to answer crucial questions about how diversity arose and how one might best act to maintain it (Gaston 2000, Purvis \& Hector 2000). This is of particular importance in enclosed and semi-enclosed marine ecosystems, such as the Mediterranean Sea, which are highly sensitive to human impact (Caddy 1993, Mazouni \& Rey-Valette 2002). 
In the Mediterranean Sea, given the lack of largescale standardised surveys devoted to benthic species distribution, all previous work conducted on a Mediterranean scale has been based on pooled knowledge derived from earlier published studies (Pérès \& Picard 1958, Pérès 1967, Bacescu 1985, Tortonese 1985, Garibaldi \& Caddy 1998, Bianchi \& Morri 2000, Quignard \& Tomasini 2000, Arvanitidis et al. 2002). Although exclusively based on empirical comparisons of disparate regional data sets mainly collected before the 1980s, these studies still offer the best - and the only available picture of the spatial patterns of species richness on a Mediterranean scale. All the faunistic groups considered in these works (benthic invertebrates, fishes) exhibited a single organisational pattern of species richness, characterised by a large-scale eastward decline in species number. This longitudinal gradient has been explained by the combined action of various factors of natural origin, among which Atlantic inflow was suspected of playing a major role (Pérès \& Picard 1958, Pérès 1967, Bacescu 1985, Bianchi \& Morri 2000). With the re-opening of the Strait of Gibraltar at the dawn of the Pliocene (5 million years ago), the penetration of Atlantic flora and fauna with the incoming flux of water from west to east is likely to have served as a diversity pump (Harmelin \& D'Hont 1993, Bianchi \& Morri 2000, Quignard \& Tomasini 2000).

In addition, several factors of anthropogenic origin are suspected of having played an increasingly important role with regard to Mediterranean species diversity (Bianchi \& Morri 2000). From the opening of the Suez Canal in the middle of the 19th century, an influx of species from the Red Sea, referred to as Lessepsian immigration, increased the species richness of the south-eastern Mediterranean (Por 1989, Bianchi \& Morri 2000). From this period on, some Lessepsian species have progressively extended their distribution range north-westwards (Papaconstantinou 1990, Golani et al. 2002), and recent studies have suggested that the Lessepsian immigration still persists and is even intensifying (Papaconstantinou \& Farrugio 2000, Quignard \& Tomasini 2000). In addition, since the end of the 1970s, Mediterranean coastal ecosystems have been exposed to rapid changes under anthropogenic pressures. This situation has escalated, in particular, along the northern Mediterranean coasts, which are characterised by higher human population density, fisheries and tourism development and more intensive agriculture and river run-off (Caddy 2000). Although reliable quantitative data on human impact are lacking for large-scale areas, it is acknowledged that human activities are responsible for strong nutrient enrichment and an increase in fisheries production, which has entailed full to over exploitation of most of the demersal resources and led to profound alterations in benthic habitats (Stergiou et al. 1997, Papaconstantinou \& Farrugio 2000).

Despite the potentially dramatic consequences of the increase in human pressure and our limited knowledge on Mediterranean diversity, no study to date has offered a quantified picture of current diversity patterns in the Mediterranean Sea on the basis of standardised and recent data sets. The aim of the present study is to fill this gap and to provide a first description of the reference state for the large-scale species richness pattern of groundfishes in the northern Mediterranean Sea. For this purpose, we used data collected during the MEDITS programme (Bertrand et al. 2002a), the first large-scale survey carried out with a single sampling design on the continental shelf of the whole northern Mediterranean Sea. We dealt with the species richness pattern in fish demersal assemblages at coarse scales, in order to compare our results with earlier works - only based on comparisons between large biogeographical zones - and we enhanced the study with a finer scale of analysis (inter-regional comparison). The questions addressed in this study were 2-fold. (1) Does the longitudinal gradient of species richness-mainly attributed to the Atlantic influence - still persist in the northern Mediterranean Sea? (2) Does the scale of analysis influence the assessment of diversity patterns within the northern Mediterranean Sea?

\section{MATERIALS AND METHODS}

Study zone and sampling design. We analysed data collected from annual bottom trawl surveys performed in spring (May and June) from 1996 to 1998 over the continental shelves (10 to $200 \mathrm{~m}$ depth) of the northern Mediterranean Sea, within the framework of the MEDITS project (Bertrand et al. 2002a). This project was primarily undertaken to obtain fisheries-independent data on demersal resources in a zone characterised by the lack of reliable information on the exploitation patterns of fishing fleets. In the present study, we considered only benthos-associated fishes, and, thus, pelagic species caught sporadically were not taken into account in the analysis.

Due to its large size - more than $5000 \mathrm{~km}$ of coastline shared by several countries - the study zone was divided into 23 operative sub-areas (MEDITS regions) (Fig. 1). These operative sub-areas were defined by the scientific teams in charge of the surveys on the basis of both sampling and administrative constraints and knowledge of the environmental and anthropogenic characteristics of the surveyed areas (Bertrand et al. 2002a). In each sub-area, a stratified, randomsampling design based on bathymetric strata (10-50, 


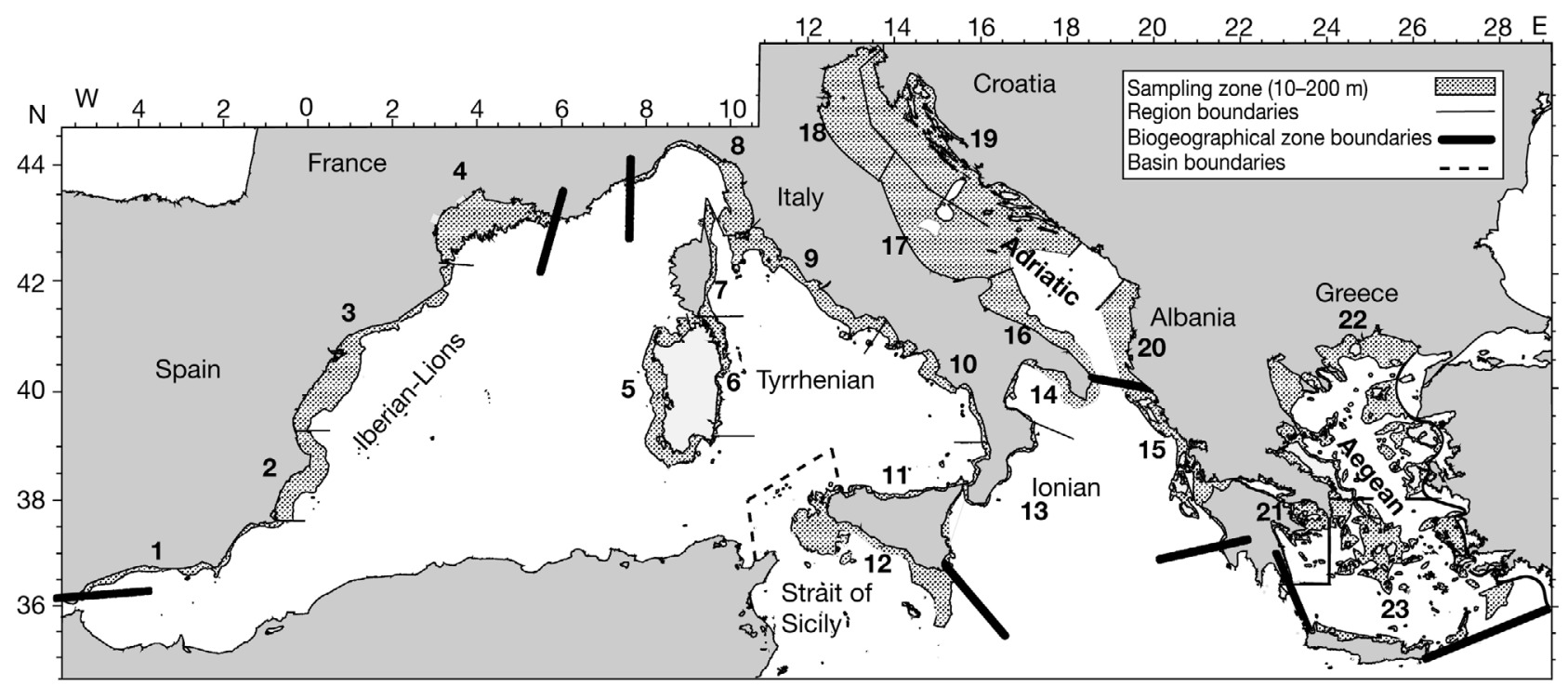

Fig. 1. Map of the area studied with spatial boundaries. Area codes: 1, North Alboran Sea; 2, Alicante area; 3, Catalan Sea; 4, Gulf of Lions; 5, West Sardinian; 6, East Sardinian; 7, East Corsica; 8, Ligurian Sea; 9, North East Tyrrhenian; 10, South East Tyrrhenian; 11, South Tyrrhenian; 12, Strait of Sicily; 13, South West Ionian; 14, North West Ionian; 15, East Ionian; 16, South West Adriatic; 17, Centre West Adriatic; 18, North West Adriatic; 19, Croatia; 20, Albania; 21, Argosaronic area; 22, North Aegean; 23, South Aegean

50-100, 100-200 m) was applied. All the sub-areas and strata were sampled in each of the 3 surveys performed in 1996, 1997 and 1998. The sampling procedures of these surveys were standardised according to a common protocol, including the use of the same gear and the same sampling strategy for the whole zone studied and during the whole period studied. The standard device was a bottom trawl (GOC 73) with $20 \mathrm{~mm}$ cod-end mesh size (stretched mesh). The vertical opening of the gear was about $2 \mathrm{~m}$, and its wing spread about $18 \mathrm{~m}$ (Bertrand et al. 2002b). All the tows were performed during daylight hours. Speed on the ground and duration of the tows were standardised at 3 knots and $30 \mathrm{~min}$, respectively. Information recorded by an underwater Scanmar system-to control the trawl geometry (horizontal and vertical openings, contact with the bottom) - allowed us to eliminate the tows that had not been properly carried out.

For the present study, we considered 3 spatial scales: regions, defined as the operative sub-areas described above, basins and biogeographical zones; the latter 2 levels corresponded to those often adopted in previous studies (Fig. 1). Thus, as is widely accepted, the western basin was separated from the eastern basin by the Siculo-Tunisian sill. These 2 basins are known to differ with regard to both physical and biological features (Bacescu 1985, Estrada 1996). Similarly, the 5 biogeographical zones considered (Iberian-Lions zone, Tyrrhenian Sea, Ionian Sea, Adriatic Sea and Aegean Sea) represent geomorphological sub-basins, being separated from each other by straits and sills and each having a distinctive oceanographic regime. For further details on the biological and geomorphological characteristics of these zones, see Bacescu (1985), Le Vourch et al. (1992), Stergiou et al. (1997), Millot (1999), or Arvanitidis et al. (2002).

Descriptors and statistical analyses. As stated by Maguran (2004), there are 2 main methods for expressing estimates of species richness: the number of species per specified number of individuals (numerical species richness), or the number of species per unit area (also called species density). The characteristics of the MEDITS survey, as well as the objective of comparing our results with those of previous studies (all based on estimates of number of species per area), led us to estimate species richness patterns through the number of species per unit area. This strategy is also consistent with most ecological comparisons of biodiversity, which are mainly comparisons of species density (Gotelli \& Colwell 2001). Furthermore, this approach appeared to be particularly relevant 'for conservation purposes and applied problems that focus on large areas' (Gotelli \& Colwell 2001), as is the case for our study.

Because species richness is sensitive to sample size, only tows showing low variation in the surface area trawled were considered. Thus, among the 1972 tows sampled during the period studied, only 1914 were included in the analyses (mean $\pm \mathrm{SD}: 0.05 \pm 0.003 \mathrm{~km}^{2}$ ). There was no positive correlation between species richness and the trawled surface area for the 1914 selected tows. The weakness of both the coefficient of 
Spearman rank correlation $(\mathrm{r}=0.08)$ and the Cramer's association coefficient (Agresti 1992; $V=0.1$ ) — where $V$ increases between 0 and 1 with the association of the 2 variables studied - showed that the association between these 2 variables can be considered as negligible for the set of selected tows.

Universal definitions of scales to describe diversity do not exist. According to Harrison et al. (1992), the choice of scale is entirely arbitrary. Here, local species richness was taken to mean the number of species at a site (i.e. trawl station), and the total species richness estimates per area (regions, biogeographic zones and basins) were based on the Chao2 estimate of species richness. We used the Chao2 estimator because it is acknowledged to provide a better estimate of true species richness than observed species richness, especially for situations in which the number of samples is small (Colwell \& Coddington 1994, Maguran 2004). In our work, this property seemed to be particularly relevant in the assessment of total species richness for the least sampled regions.

The Chao2 estimate of species richness equals $S_{\text {obs }}+$ $\left(Q_{1}\right)^{2} / 2\left(Q_{2}\right)$, where $S_{\text {obs }}$ is the total number of species observed in the area considered, $Q_{1}$ is the number of species occurring at 1 station of the corresponding area and $Q_{2}$ is the number of species occurring at 2 stations.

We completed these analyses by computing both mean species richness and beta diversity, which are the 2 basic components governing the total number of species in a given area (Whittaker 1972). Mean species richness is the mean number of species per tow for a given area; its spatial heterogeneity has been tested at each of the scales studied, using analysis of variance (ANOVA) and Fisher's least significant difference (LSD method; Koopmans 1981). In a preliminary step, we carried out analyses according to generalised linear models (GLMs; McCullagh \& Nelder 1989), to check whether large-scale spatial patterns in mean species richness could be modified by bathymetric and year effects. The link functions were identity, and the error term was assumed to be normally distributed. For each of the 3 spatial scales studied, a GLM allowed the assessment of mean species richness per area after adjustment for both the bathymetry and year effects (least square means). We found that both the year of sampling and the depth stratum had a negligible effect on mean species richness patterns. The weakness of these 2 effects is clearly shown by the strong linear regression between least square means (i.e. mean species richness adjusted by depth and year effects) and non-adjusted mean species richness. Both the coefficient of determination $\left(\mathrm{r}^{2}\right)$ and the slope of the association (a) between adjusted and non-adjusted mean species richness were very close to $1\left(\mathrm{r}^{2}=0.98\right.$ and $a=$ 1.005 at the regional scale; $r^{2}=0.99$ and $a=1.09$ at the biogeographical scale). This showed that our perception of spatial diversity patterns is not highly modified by the influence of year and depth stratum.

Consequently, all further analyses of the spatial pattern in mean species richness only showed ANOVA results based on the 'non-adjusted' estimates of mean species richness. All observations belonging to the same spatial unit (basin, biogeographical zone, region) were divided by their SD before the ANOVAs were conducted to stabilise the variances. When the null hypothesis - that all means are equal — was rejected, the means were ordered into different levels using the LSD method. This method - designed to perform all pairwise comparisons among the means - has been used to organise all the spatial units for a given scale into a hierarchy, according to their mean species richness.

Finally, we studied beta diversity, which measures the change in the composition of the species list within a given area. We used Whittaker's index $\left(\beta_{\mathrm{w}}\right)$ as a measure of beta diversity, because it is the index most widely described in previous studies and because it is considered as one of the simplest and best measures of beta diversity (Wilson \& Shmida 1984, Maguran 2004). $\beta_{\mathrm{w}}$ was measured over 2 scales (regional and biogeographical zones), such that:

$$
\beta_{\mathrm{w}}=\frac{S}{\bar{\alpha}}
$$

where $S$ is the Chao2 estimate of the total number of species in the area considered and $\bar{\alpha}$ is the average number of species per trawl station in the corresponding area. $\beta_{\mathrm{w}}$ measures the proportion by which the whole area (region or biogeographical zone) is richer than the average sites within it (Ellingsen 2001).

Because the number of sampled hauls varies between regions, biogeographical zones and, to a lesser extent, basins, between-area comparisons based on the total number of recorded species (i.e. Chao2 and Whittaker) are vulnerable to sample size bias. We used sample-based rarefaction curves to overcome this problem (Maguran 2004). For a given area - where $N$ is the total number of sampled tows - the corresponding rarefaction curve is produced by repeatedly resampling the pool of $\mathrm{N}$ samples, at random, plotting the average estimate of Chao2 (or $\beta_{\mathrm{w}}$ according to case) represented by $2,3, \ldots, \mathrm{N}$ samples (see Gotelli \& Colwell 2001). Rarefaction curves are then used to compare the estimates of species diversity of several assemblages at a common lower sample level. Rarefaction curves were based on $p$ randomisations of the sites sampled in each area $(p=100$ for the regions and 50 for the basins and biogeographical zones). Rarefaction curves based on Chao2 were performed using EstimateS software (Colwell 2000), while all the other statistical analyses were performed using SAS (SAS/STAT 1992). 
Sampling standardisation. Several vessels were used simultaneously in order to complete the sampling of the whole zone during a short period of the year (May and June), and the work at sea was divided up between several teams. Possible variability of accuracy in species identification between the different teams could bias the analysis of spatial patterns of species richness. However, restricting our analysis to the groundfish strongly limited the significance of such a bias. Fish were the main target group of the surveys, and several specialists in fish identification were on board during the surveys in each of the regions studied. In addition, groundfishes appeared to be easier to identify at the species level than other benthic faunistic groups such as crustaceans and cephalopods.

While boundaries between basins and biogeographical zones were defined on the basis of widely accepted geomorphological and ecological features, the limits of the MEDITS regions were partly determined by technical and administrative constraints. A few areas of the study zone have not been sampled for geomorphological reasons (e.g. the area between Regions 4 and 8 was not sampled due to its topography) or because of political factors (e.g. the area between Regions 19 and 20 was not sampled because Montenegro was not involved in the MEDITS programme). In addition, the type of sampling design (not systematic sampling but random allocation of samples in each stratum and region), some field constraints (meteorological events, breakage of equipment, vessel failure, etc.) and elimination of poorly standardised tows have resulted in other areas of spatial discontinuity in the sampling effort. This discontinuity in sampling limited our ability to identify small-scale species richness structures. Consequently, we used the operative MEDITS regions as the finest level of resolution to analyse species diversity patterns. This regional scale offers the finest scale of observation ever used to investigate diversity patterns within the entire northern Mediterranean Sea.

Otherwise, because the main goal of the present work - which was to describe an initial reference state for the spatial patterns of groundfish diversity in the whole northern Mediterranean Sea - required working with the best-validated and standardised data, we restricted our analysis to 3 surveys performed from 1996 to 1998. These data have been subjected to a strict - and extensive - validation process by all MEDITS teams, and they appeared to be the most standardised at the scale of the entire study area. The main problem — which was not limited to this period concerned sampling off Corsica. The coastal stratum (10 to $50 \mathrm{~m}$ ) of this region was not sampled because of topographic constraints and the massive presence of Posidonia beds, which prevented reproducible sampling. Despite our objective to maintain the highest standardisation level possible, the surveys conducted after 1998 suffered from several other standardisation problems. For instance, the entire Croatian coast was not sampled in 1999, for political reasons. Thus, to avoid the risk of inter-annual variations in the sampling design disturbing our perception of the spatial patterns, we have limited our study on species richness patterns to the 3 best-validated surveys. This still offers the most extensive data set ever studied for the benthic and demersal fish assemblages of the Mediterranean Sea.

For the period studied, total species richness was not estimated for Corsica, because it has been widely reported for the world's oceans - and specifically for groundfishes in this region (Gaertner et al. 2005a) that the presence of certain species widely varies according to depth. The lack of samples in the coastal stratum would have artificially reduced the assessment of overall species richness for this region and thus biased inter-regional comparisons based on estimates of total species richness. In contrast, we showed that species richness per tow was not strongly influenced by depth (see above). Thus, we assumed that the assessment of mean species richness per area (i.e. the mean number of species per tow for the corresponding area) is not strongly influenced by depth either. Consequently, Corsica was included in the analysis of regional pattern for mean species richness.

\section{RESULTS}

\section{Estimates of species richness}

Representatives of 98 groundfish species belonging to 41 families were found in the 1914 samples that were analysed (Table 1). None of them belonged to the Lessepsian immigrants. The number of species recorded between the 2 basins only varied from 96 to 97 . In addition, 95 species were caught in both eastern and western basins, indicating strong homogeneity in the species list between the 2 basins.

Rarefaction curves based on the Chao2 estimator allowed comparison of species richness at each of the scales studied (Fig. 2). In numerous cases - mainly at the regional scale-rarefaction curves did not reach an asymptotic maximum, suggesting that the corresponding estimation of species richness should only be seen as a lower boundary. On the other hand, most of the curves suggested that increasing the sampling effort would reveal few additional species, indicating that most of the areas studied were thoroughly sampled by these surveys. This result implies that - even for the least sampled regions such as the North Albo- 
Table 1. List of the species sampled, sorted by family

\begin{tabular}{|c|c|}
\hline Family & Species \\
\hline ARGENTINIDAE & Argentina sphyraena Linnaeus, 1758; Glossanodon leioglossus (Valenciennes, 1848) \\
\hline BLENNIDAE & Blennius ocellaris Linnaeus, 1758 \\
\hline BOTHIDAE & $\begin{array}{l}\text { Arnoglossus imperialis (Rafinesque, 1810); Arnoglossus laterna (Walbaum, 1792); } \\
\text { Arnoglossus rueppelii (Cocco, 1844); Arnoglossus thori Kyle, 1913; } \\
\text { Bothus podas (Delaroche, 1809) }\end{array}$ \\
\hline CALLIONYMIDAE & Synchiropus phaeton (Günther, 1861); Callionymus maculatus Rafinesque, 1810 \\
\hline CAPROIDAE & Capros aper (Linnaeus, 1758) \\
\hline CARAPIDAE & Carapus acus (Brunnich, 1768) \\
\hline CENTRACANTHIDAE & $\begin{array}{l}\text { Centracanthus cirrus Rafinesque, 1810; Spicara flexuosa Rafinesque, 1810; } \\
\text { Spicara maena (Linnaeus, 1758); Spicara smaris (Linnaeus, 1758) }\end{array}$ \\
\hline CEPOLIDAE & Cepola macrophthalma Linnaeus, 1758 \\
\hline CHLOROPHTHALMIDAE & Chlorophthalmus agassizi Bonaparte, 1840 \\
\hline CITHARIDAE & Citharus linguatula (Linnaeus, 1758) \\
\hline CONGRIDAE & Conger conger (Linnaeus, 1758); Gnathophis mystax (Delaroche, 1809) \\
\hline CYNOGLOSSIDAE & Symphurus ligatus (Cocco, 1844); Symphurus nigrescens Rafinesque, 1810 \\
\hline DASYATIDAE & Dasyatis pastinaca (Linnaeus, 1758) \\
\hline GADIDAE & $\begin{array}{l}\text { Gadiculus argenteus (Guichenot, 1850); Gaidropsarus biscayensis Collett, 1890; } \\
\text { Gaidropsarus mediterraneaus (Linnaeus, 1758); Merlangius merlangus (Linnaeus, 1758); } \\
\text { Micromesistius poutassou (Risso, 1826); Phycis blennoides (Brünnich, 1768); } \\
\text { Trisopterus minutus (Linnaeus, 1758) }\end{array}$ \\
\hline GOBIIDAE & $\begin{array}{l}\text { Aphia minuta De Buen, 1931; Deltentosteus quadrimaculatus (Valenciennes, 1837); } \\
\text { Gobius niger Linnaeus, 1758; Lesueurigobius friesii Malm, } 1874\end{array}$ \\
\hline LOPHIIDAE & Lophius budegassa Spinola, 1807; Lophius piscatorius (Linnaeus, 1758) \\
\hline LOTIDAE & Molva dypterygia (Pennant, 1784) \\
\hline MACRORAMPHOSIDAE & Macroramphosus scolopax (Linnaeus, 1758) \\
\hline MACROURIDAE & Coelorynchus coeloryncus (Risso, 1810) \\
\hline MERLUCIIDAE & Merluccius merluccius smiridus (Linnaeus, 1758) \\
\hline MULLIDAE & Mullus barbatus barbatus Linnaeus, 1758; Mullus surmuletus Linnaeus, 1758 \\
\hline NETTASTOMATIDAE & Nettastoma melanurum Rafinesque, 1810 \\
\hline OPHICHTHIDAE & Echelus myrus (Linnaeus, 1758); Ophichthus rufus (Rafinesque, 1810) \\
\hline PERISTEDIIDAE & Peristedion cataphractum (Linnaeus, 1758) \\
\hline RAJIDAE & $\begin{array}{l}\text { Raja asterias Delaroche, 1809; Raja clavata Linnaeus, 1758; Raja miraletus Linnaeus, 1758; } \\
\text { Raja montagui Fowler, 1910; Raja oxyrinchus Linnaeus, 1758; Raja polystigma Regan, } 1923\end{array}$ \\
\hline SCOPHTAMIDAE & $\begin{array}{l}\text { Lepidorhombus boscii (Risso, 1810); Lepidorhombus whiffiagonis (Walbaum, 1792); } \\
\text { Scophthalmus rhombus (Linnaeus, 1758) }\end{array}$ \\
\hline SCORPAENIDAE & $\begin{array}{l}\text { Helicolenus dactylopterus Delaroche, 1809; Scorpaena elongata Cadenat, 1943; } \\
\text { Scorpaena notata Rafinesque, 1810; Scorpaena porcus Linnaeus, 1758; } \\
\text { Scorpaena scrofa Linnaeus, } 1758\end{array}$ \\
\hline SCYLIORHINIDAE & Galeus melastomus (Vaillant, 1888); Scyliorhinus canicula (Linnaeus, 1758) \\
\hline SERRANIDAE & Serranus cabrilla (Linnaeus, 1758); Serranus hepatus (Linnaeus, 1758) \\
\hline SOLEIDAE & $\begin{array}{l}\text { Buglossidium luteum (Risso, 1810); Microchirus variegatus (Donovan, 1808); } \\
\text { Monochirus hispidus Rafinesque, 1814; Solea solea (Linnaeus, 1758); } \\
\text { Synapturichthys kleinii (Risso, 1827) }\end{array}$ \\
\hline SPARIDAE & $\begin{array}{l}\text { Boops boops (Linnaeus, 1758); Diplodus annularis (Linnaeus, 1758); } \\
\text { Diplodus vulgaris (Geoffroy St Hilaire, 1817); Lithognathus mormyrus (Linnaeus, 1758); } \\
\text { Pagellus acarne (Risso, 1826); Pagellus bogaraveo (Brumich, 1768); } \\
\text { Pagellus erythrinus (Linnaeus, 1758); Pagrus (Sparus) pagrus (Linnaeus, 1758) }\end{array}$ \\
\hline SQUALIDAE & Squalus acanthias Linnaeus, 1758; Squalus blainville (Risso, 1827) \\
\hline STERNOPTYCHIDAE & Maurolicus muelleri (Gmelin, 1789) \\
\hline SYNODONTIDAE & Synodus saurus (Linnaeus, 1758) \\
\hline TORPEDINIDAE & Torpedo marmorata Risso, 1810; Torpedo nobiliana (Bonaparte, 1835) \\
\hline TRACHINIDAE & Trachinus draco Linnaeus, 1758; Trachinus radiatus Cuvier, 1829 \\
\hline TRIAKIDAE & Mustelus mustelus (Linnaeus, 1758) \\
\hline TRICHIURIDAE & Lepidopus caudatus (Euphrasen, 1788) \\
\hline TRIGLIDAE & $\begin{array}{l}\text { Aspitrigla cuculus (Linnaeus, 1758); Chelidonichthys gurnardus (Linnaeus, 1758); } \\
\text { Chelidonichthys lucernus (Linnaeus, 1758); Chelidonichthys lastoviza (Bonaterre, 1788); } \\
\text { Chelidonichthys obscurus (Bloch \& Schneider, 1801); Lepidotrigla cavillone (Lacepède, 1801); } \\
\text { Lepidotrigla dieuzeidei (Lacépède, 1801); Trigla lyra Linnaeus, } 1758\end{array}$ \\
\hline URANOSCOPIDAE & Uranoscopus scaber Linnaeus, 1758 \\
\hline ZEIDAE & Zeus faber Linnaeus, 1758 \\
\hline
\end{tabular}



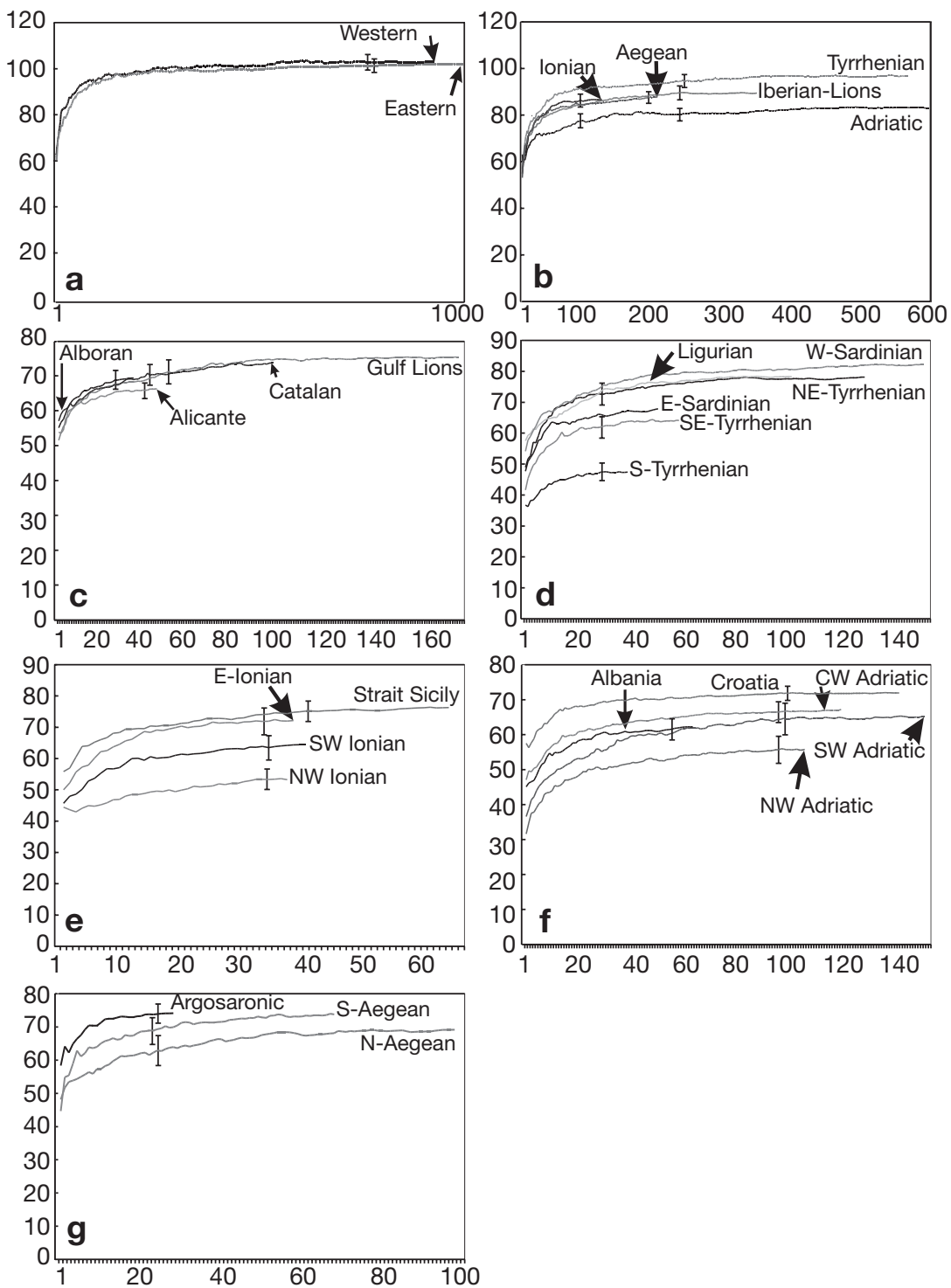

Fig. 2. Rarefaction curves for each area at the (a) basin scale, (b) biogeographical zone scale and (c to g) regional scale within each biogeographical zone (c: Iberian-Lions; d: Tyrrhenian; e: Ionian and Strait of Sicily; f: Adriatic; g: Aegean). Plotted values on the ordinate are means of $p$-estimates of Chao2 based on $p$ randomizations of the stations sampled in each area ( $p=100$ for regions and 50 for basins and biogeographical zones), according to the number of stations sampled (on the abscissa). For clarity, error bars (indicating $\pm \mathrm{SD}$ ) are only occasionally given as examples of the variability among simulations for a given number of tows

ran Sea or the Argosaronic area - rarefaction curves based on the Chao2 estimator can be used to analyse the spatial pattern in species richness.

Spatial heterogeneity in species richness was stronger at our finer scales than at the basin scale. Otherwise, at the scale of biogeographical zones, the Adriatic Sea clearly appeared to be the poorest zone in the northern Mediterranean Sea (Fig. 2b). At a finer scale, the South Tyrrhenian, NW Ionian, NW Adriatic and North Aegean areas appear to be the least species-diverse regions of the respective seas (see Fig. 2c to g). Along the eastern coast of the Tyrrhenian Sea, the northern areas were richer than the southern ones (Fig. 2d). Finally, the east coast of the Ionian Sea was richer than the west coast (Fig. 2e).

\section{Spatial patterns in mean species richness}

Mean species richness showed no relationship with the number of tows carried out in the corresponding areas (e.g. Spearman rank correlation, $r=$ $-0.11, \mathrm{p}=0.614$ at the regional scale). The analysis of spatial patterns in terms of mean species richness showed significant heterogeneity at each of the 3 scales studied (ANOVAs, $p<0.01$; Table $2 \mathrm{a}-\mathrm{c})$. At each scale, mean values in species richness of spatial units were sorted in decreasing order into different levels according to the LSD method ( $p<0.01)$. Spatial units sharing the same level did not show significant differences in mean species richness. At the largest scale, species richness appeared to be significantly higher in the western basin than in the eastern one (Table 2a). At an intermediate scale (biogeographical zones-Table 2b), the Iberian-Lions zone exhibited the highest mean species richness, while the Ionian and Adriatic Seas were characterised by the lowest values. The eastward decrease observed at the basin scale here appeared to be disturbed by the situation in the Aegean Sea. Furthermore, comparison between the values (mean and SD) calculated from one spatial unit to another showed that variations in species richness can be of limited importance, even when they are highly significant $(p<0.01)$. In short, our large-scale results showed a significant, but moderate, and sometimes disturbed, pattern of mean species richness decreasing eastwards along the whole northern Mediterranean shelf.

The spatial pattern appeared to be very different at the smallest scale of analysis (regional level). In Table 2c, one region might be represented by several levels (LSD method) when its mean species richness is 


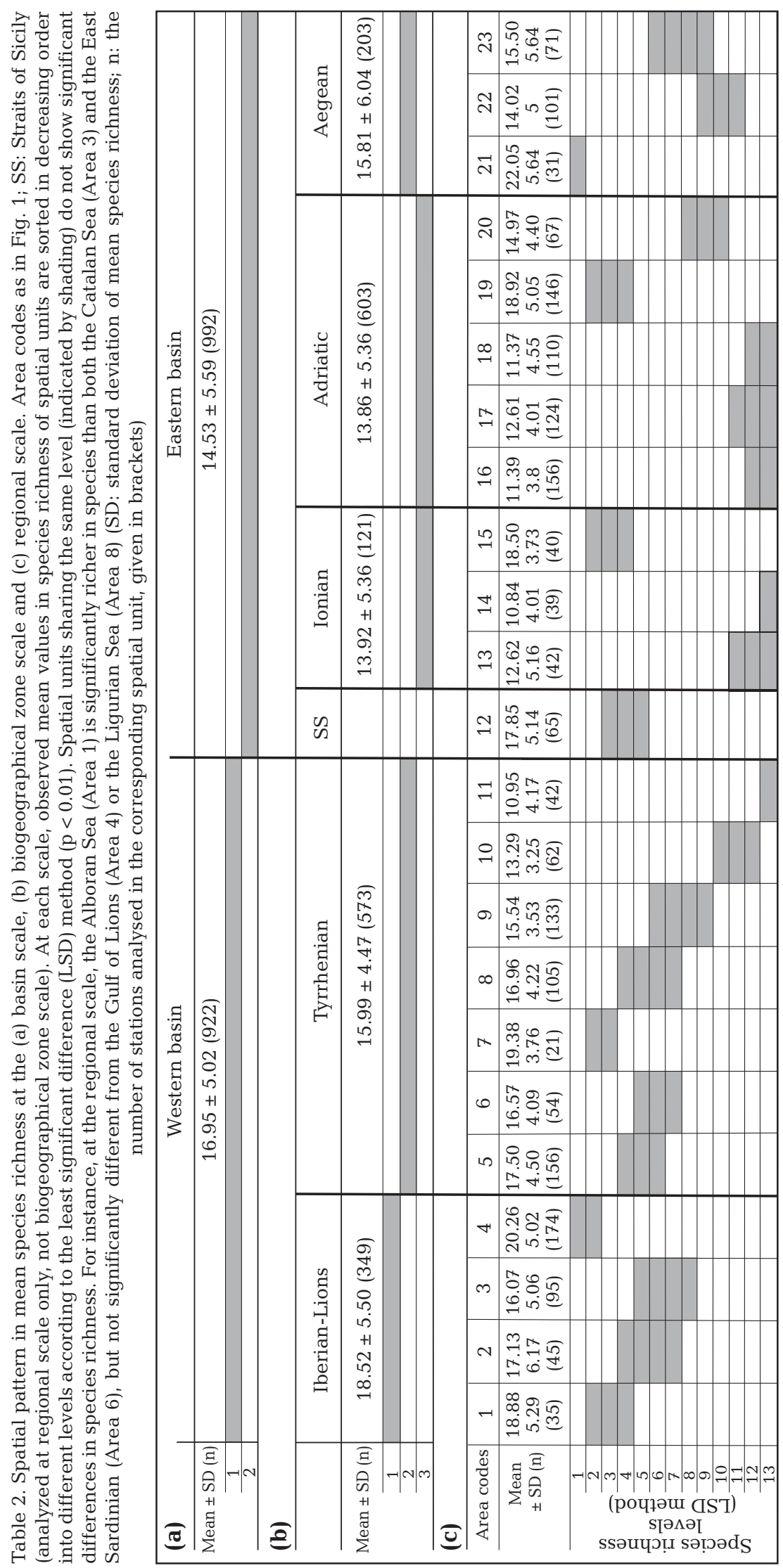

not significantly different from several other regions or groups of regions. For instance, the Gulf of Lions (Area 4) was represented by 2 LSD levels, because its mean species richness was not significantly different from that in the Argosaronic area (Area 21) or that in a group of regions represented by the North Alboran Sea (Area 1), East Corsica (7) and the East Ionian (15) and NE Adriatic Seas (19). In contrast, mean species richness in the latter regions (Areas 1, 7, 15 and 19) was different from that observed in the Argosaronic area ( $p<$ 0.01).

At this scale of analysis, the expected single and progressive longitudinal decrease in species richness was replaced by high inter-regional heterogeneity, which occurred even between regions belonging to the same biogeographical zone. For instance, within the Tyrrhenian zone, Corsica (Area 7) and West Sardinia (Area 5) were far richer than the South Tyrrhenian Sea (Area 11). More generally, we found that the northern areas of this biogeographical zone were significantly richer than the southern areas in both the western (East Corsica richer than East Sardinian) and the eastern parts (see the decreasing gradient between the Ligurian Sea and the South Tyrrhenian area). Similarly although the Ionian and Adriatic Seas showed the lowest levels of species richness at the biogeographical scale, some regions in these 2 seas were among the richest of the entire study zone (see Areas 15 and 19). In the Aegean Sea, the Argosaronic region (Area 21) showed the highest regional mean of the whole zone studied $(22.05 \pm 5.64)$, while the 2 other regions were by far the poorest. Only the Iberian-Lions zone showed higher homogeneity between its regions.

\section{Analysis of beta diversity}

Because the comparison between areas based on $\beta_{\mathrm{w}}$ can be partly influenced by differences in sample size, cumulative beta diversity has been plotted against the number of tows for each 
area (Fig. 3). At the biogeographical scale, variation in beta diversity was low between most of the zones (Fig. 3a). Only the Iberian-Lions zone was clearly distinguished from the others. This zone showed the lowest beta diversity, indicating greater within-zone homogeneity of the recorded species compared with the 4 other biogeographical zones.

At the regional scale, regions belonging to the Tyrrhenian Sea (5 to 11) showed the highest within-zone homogeneity in beta diversity (Fig. 3b). This suggests that, in this biogeographical zone, the degree of spatial segregation does not strongly vary between regions. Regions belonging to both the Adriatic Sea (16 to 20) and the Ionian Sea (13 to 15) showed the highest within-zone variability. In each of these 2 zones this heterogeneity tended to discriminate the east coast from the west coast. For example, Regions 13 and 14 (western Ionian) exhibited higher spatial heterogeneity in the species sampled than Region 15 (eastern Ionian). Similarly, Croatia (Area 19) and Albania

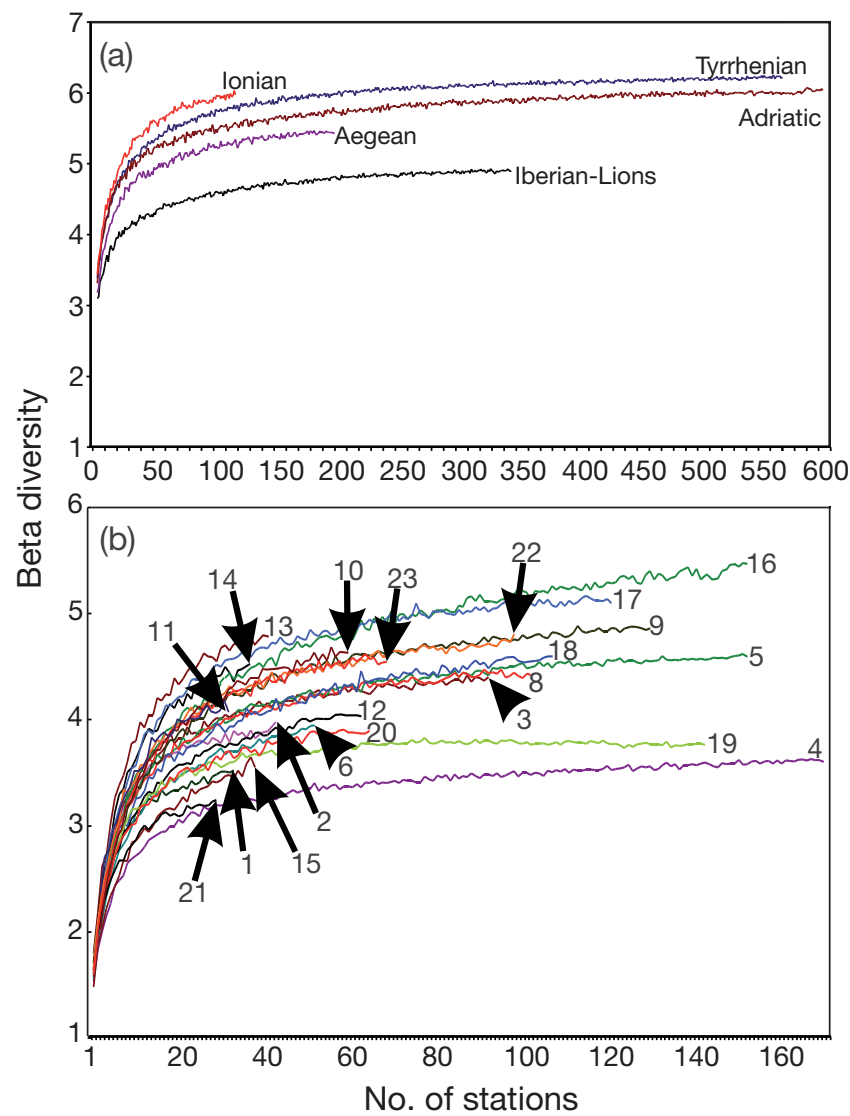

Fig. 3. Cumulative beta diversity (Whittaker's index) against number of stations at the scale of (a) biogeographical zones and (b) regions. Area codes as in Fig. 1. Plotted values are means of $p$-estimates of Whittaker's index based on $p$ randomizations of the sites sampled in each area $(p=100$ for the regions and 50 for the basins and biogeographical zones)
(Area 20), which belong to the eastern Adriatic Sea, showed a lower beta diversity (i.e. higher withinregion homogeneity) than the values recorded for regions belonging to the south-west and centre-west of the Adriatic Sea (Areas 16 and 17).

\section{Local versus regional species richness}

Analysis of the relationship between local richness (mean species richness) and larger scale richness provides information on the reproducibility of the spatial pattern of species richness at different scales (Fig. 4). At the regional scale, we determined a positive linear relationship between local and regional diversity $\left(\mathrm{r}^{2}=0.53\right.$, $\mathrm{p}=0.00016$; Fig. 4b). At the biogeographical scale, the linear relationship was non-significant $\left(\mathrm{r}^{2}=0.24\right.$, $p=0.39$ ). However, the low number of biogeographical zones limited our ability to reliably assess the type of relationship at this scale.

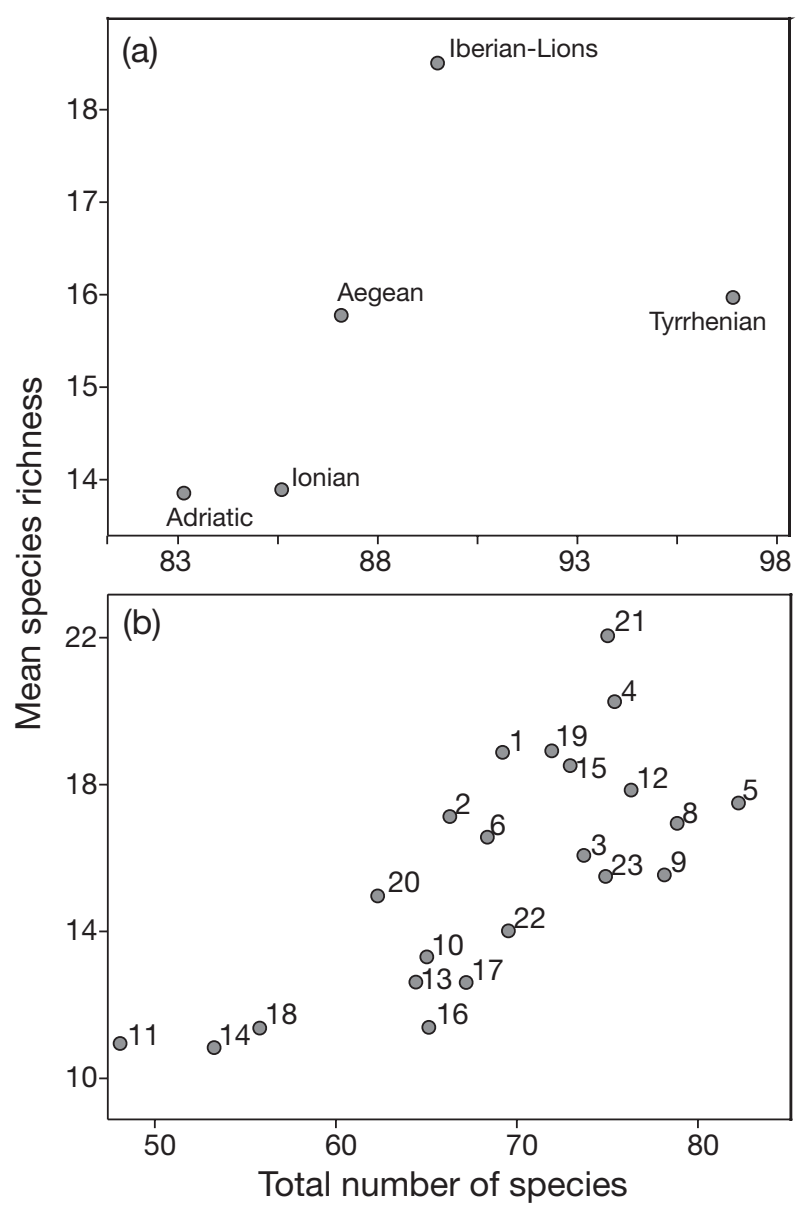

Fig. 4. Relationship between mean species richness and total species richness (Chao2) at the (a) scale of biogeographical zones or (b) regional scale. Area codes as in Fig. 1 


\section{DISCUSSION}

The analysis of groundfish diversity carried out in this work is based on a comprehensive sampling effort (never before achieved in the Mediterranean Sea at such a large scale and very rarely - if ever - carried out elsewhere in the world for the purpose of assessing fish diversity using a single, standardised design). Despite the high sampling intensity (992 tows for the eastern basin only), no Lessepsian immigrant species (see reference lists of Lessepsian fishes in Quignard \& Tomasini 2000 and in Golani et al. 2002) was caught during the 3 surveys performed between 1996 and 1998. The additional analysis of 3 other MEDITS surveys performed on the continental shelf of the same study zone in 1999 (643 tows), 2000 (680 tows) and 2001 (675 tows) also showed the total lack of groundfish Lessepsian migrants. This means that not 1 Lessepsian migrant was caught at the 3912 stations surveyed on the continental shelf of the whole northern Mediterranean Sea during the 6 MEDITS surveys performed between 1996 and 2001. Given the alterations induced by some Lessepsian species with regard to both regional diversity and fisheries in the Levant Sea (Papaconstantinou \& Farrugio 2000), the monitoring of their current north-westward spread is of interest for ecosystem and resources management. Our results clearly suggest that, for the period studied, Lessepsian species no longer strongly influence the organisation of softsediment groundfish assemblages on the continental shelf of the northern Mediterranean Sea. Nevertheless, the very clear conclusions that our results would appear to suggest should be tempered by the fact that: (1) our work does not offer an exhaustive picture of the groundfish species list in the study zone (see Fig. 2) and that (2) a significant proportion of the Lessepsian species belong to the pelagic environment.

\section{Local versus regional diversity}

The relationship between local and regional richness suggests a linear trend (Fig. 4). The linear positive relationship observed between regional and local diversity could suggest that assemblages were subject to successful invasion by species from the regional pool (unsaturated assemblages; see Ricklefs 1987). This result seems to be consistent with most of the marine field studies that have demonstrated the prevalence of unsaturated assemblages (see references in Rivadeneira et al. 2002), supporting the idea that regional processes control local diversity.

However, several critical reviews point out that the general lack of evidence showing saturated communities in most marine and terrestrial field studies could be explained by certain methodological problems or artefacts (Srivastava 1999, Gaston 2000, Loreau 2000). Most of the time - as in our case-data sets used in these studies were not sampled with the initial goal of testing for saturation/unsaturation of assemblages, and do not satisfy all the conditions necessary to deal with this issue. For instance, Rivadeneira et al. (2002) argued that in most published studies the local scale used to evaluate species' interactions was too large to detect the effect of species' interactions. Strong species' interactions and, therefore, saturated patterns would be found only if the spatial scale at which local diversity is measured were small enough for the habitat to be homogeneous and for all species to be able to encounter each other within ecological time and so, possibly, to interact (Huston 1999, Srivastava 1999). In marine ecosystems such a requirement is particularly difficult - if not impossible (see Gray 2002) - to satisfy, because of obstacles to field access, incomplete knowledge of benthic habitats and the fact that no habitat is truly homogeneous. Furthermore, the difficulty of properly defining a relevant local scale is exacerbated by the fact that it depends on the taxa considered. A habitat can be homogeneous for one type of taxon, but heterogeneous for another. Similarly, the spatial scale at which competition could potentially occur also varies with biological and ecological traits, such as the degree of mobility of the species studied. The size of the local scale adopted for the present analysis of groundfishes $\left(0.5 \mathrm{~km}^{2}\right)$ is small enough for all species to be able to encounter each other within ecological time. However, even if we limited our study exclusively to soft-sediment areas, we cannot guarantee that each station is characterised by a homogeneous habitat. Thus, rather than coming down in favour of saturation or unsaturation of assemblages, our study highlights the difficulty of addressing this question on the basis of survey data sampled with another initial goal, as is still usually the case in the literature devoted to this issue.

\section{Beta diversity}

Although beta diversity indices provide additional information to estimates of local species richness and total species richness (Harrison et al. 1992), they have often been neglected, particularly for marine environments (Price 2002). The few investigations of beta diversity dedicated to marine systems have been focused on benthic macrofauna (see references in Ellingsen \& Gray 2002). Even for these taxa, Ellingsen (2002) admitted that there are, as yet, few studies that can be used for comparison, to determine the high and low values of beta diversity. This problem is particu- 
larly striking in our case, because beta diversity varies from one faunistic group to another (Ellingsen \& Gray 2002), and available reference values on marine fish are, to our knowledge, totally lacking. In addition, values of $\beta_{\mathrm{w}}$ also depend on the scales used to define both local and regional (or larger scale) diversity (Loreau 2000). Thus, at the present state of knowledge, comparing beta diversity with earlier works seems to be unrealistic and could lead to misinterpretation.

Nevertheless, the standardised data of our results provide a first basis for between-area comparisons of beta diversity for groundfishes within our large study zone. We have shown that $\beta_{\mathrm{w}}$ was always weak (from 3.57 to 5.45 at the regional scale; from 4.62 to 5.95 at the biogeographical scale) compared to its theoretical maximum value (when every station has a single set of species), which is equal to the number of samples recorded in the area studied (from 31 to 174 at the regional scale; from 121 to 603 at the biogeographical scale). This result suggests that beta diversity - and in turn the spatial segregation of species - is generally limited; this is consistent with earlier works, conducted in several regions of the northern Mediterranean Sea, showing that soft-sediment groundfish are generally not restricted to a single type of substratum (Gaertner et al. 1999). More generally, the high mobility of groundfish - which allows each individual to visit and occupy a wide range of habitats - could limit the beta component of the diversity for this faunistic group. Even bathymetry and correlated factors - which are known to play a dominant role in groundfish assemblage structuring - do not affect the fish species sampled as much as expected. Table 3 shows that most of the species can be found in the 3 bathymetric strata, while only a very limited number of species are confined within a single stratum. Finally, the possible unsaturation of the groundfish assemblages (meaning that specific interactions do not strongly affect the spatial extension of individuals) could also favour a good mixing of species within a given region and therefore a low level of beta diversity.

\section{Does the longitudinal gradient of species richness still persist in the northern Mediterranean Sea?}

A limited part of our results, exclusively obtained at the lowest resolution scales, might be roughly and partly consistent with earlier works showing a large-scale eastward decrease in species richness in the Mediterranean Sea (Pérès \& Picard 1958, Bacescu 1985, Tortonese 1985, Garibaldi \& Caddy 1998, Quignard \& Tomasini 2000, Arvanitidis et al. 2002). This is the case for the analyses of mean species richness patterns conducted at the basin and biogeographical scales. In contrast, the expected
Table 3. Occurrence of species (percentage) for each bathymetric stratum ( $\mathrm{N}$ : number of stations sampled in each bathymetric stratum)

\begin{tabular}{|lcccc|}
\hline Strata & N & $\begin{array}{c}\text { Occurrence } \\
(\geq \text { one time })\end{array}$ & $q$ & $\begin{array}{c}\text { Occurrence in } \\
q \text { bathymetric } \\
\text { strata }\end{array}$ \\
\hline $10-50 \mathrm{~m}$ & 468 & 82.2 & 1 & 9.1 \\
$51-100 \mathrm{~m}$ & 716 & 90.6 & 2 & 13.0 \\
$101-200 \mathrm{~m}$ & 730 & 96.2 & 3 & 77.9 \\
\hline
\end{tabular}

eastward decline in number of species did not appear in our results when using rarefaction curves. Moreover, using both rarefaction curves and mean species richness analyses (see Fig. 2b, Table 2b), the situation we report for the Aegean Sea strongly contrasts with the findings of most previous works, which considered this sea to be the least species-diverse zone within the whole northern Mediterranean Sea, for both benthic invertebrates (Pérès \& Picard 1958, Bacescu 1985) and fish (Stergiou et al. 1997, Garibaldi \& Caddy 1998, Quignard \& Tomasini 2000). The only exception is presented by the recent work of Arvanitidis et al. (2002), which shows that the species richness of polychaetes is, nowadays, higher in the Aegean Sea than in some adjacent western seas (the Tyrrhenian and Ionian Seas). Otherwise, the high similarity in the species we observed between the 2 basins strongly contrasted with the idea supported by Bacescu (1985), who considered 'the Siculo-Tunisian sill — which separates the two Mediterranean basins - as a geographical, hydrological, and climatic frontier'.

The traditional view of a single, large-scale, decreasing trend in species richness and the expected dominant influence of Atlantic inflow in the structuring of this pattern completely collapses in our regional-scale analysis. Independent of the descriptor used, we did not find any species richness trend, either with distance from the Strait of Gibraltar, or with location within the water flows of Atlantic origin (see Le Vourch et al. 1992). Even within the Tyrrhenian Sea, the increase in species richness towards the north appeared to be in the opposite direction to the progression of Atlantic waters into the Mediterranean Sea (see Millot 1999, showing that waters of Atlantic origin enter the Tyrrhenian from the south and flow northwards along the coasts). Only the situation observed in the westernmost region of the IberianLions zone might be linked to Atlantic inflow. The Alboran Sea, which is the most strongly Atlantic-influenced region, is also the species-richest along the coast of the Iberian Peninsula. The Atlantic influence in this area is mainly marked by a strong enhancement of the level of primary productivity, which contributes to the structuring of benthic invertebrate (Harmelin \& D'Hont 1993, Abelló et al. 2002) and groundfish communities (Gaertner et al. 2005b). 
Differences between species richness patterns in the present study and in previous ones - which were mainly based on data collected before the 1980s - may partly result from the recent increase in human activities in the corresponding catchment basins. For instance, the strong increase in nutrients of anthropogenic origin, which has occurred in the Aegean Sea during the last 3 decades, has been responsible for a shift from the original oligotrophic state to a mesotrophic productive condition (Stergiou et al. 1997). This shift might have played a role in the unexpectedly high species richness recently observed for both polychaetes (Arvanitidis et al. 2002) and, in the present study, for groundfish. However, in the past, the lack of a quantified and reproducible reference state for both nutrient and species richness patterns in this zone precluded pursuing this line of inquiry further. More generally, information available on human pressure in the Mediterranean Sea is scarce and heterogeneous for large-scale investigations. For instance, the lack of a reliable monitoring system for fishery landings (many omissions, uncertainties and disparities) - widely reported by both scientists and management authorities (Taquet et al. 1997, Relini et al. 1999, Jukic-Peladic et al. 2000, Papaconstantinou \& Farrugio 2000) — makes it difficult to draw a quantitative picture of the spatial variability of fishing pressure and then analyse its possible impact on species diversity patterns.

On the other hand, differences between the results of our work and those of earlier studies do not automatically imply a real alteration in species diversity patterns during the last decades. Alternatively, the differences might be associated with the scales of analysis and/or the methodological approaches used. For instance, the regional scale was the only scale of observation for which we consistently (i.e. independent of the descriptor considered) failed to find the expected longitudinal gradient of species richness. This scale was not investigated in previous studies, which all analysed diversity patterns at broader scales. Furthermore, earlier large-scale studies were all based on estimates of diversity resulting from the compilation of regional data bases previously published regarding geographical ranges of species. As pointed out by several authors, areas of the western basin have been traditionally much more intensively explored than those of the eastern basin (see Tortonese 1985). Consequently, the decreasing trend in species richness eastwards, described in former studies, could partly result from the more intensive biological research effort in the western part of the Mediterranean Sea.

Based on data collected in the course of the highest sampling standardisation effort ever achieved for a large-scale analysis of Mediterranean diversity, the present approach is less sensitive to methodological bias than those adopted in previous studies. Despite some limitations in the standardisation of the sampling design at such a large scale (see 'Materials and methods' section), our approach provides the first quantified picture of current diversity patterns in the northern Mediterranean Sea. Our findings - which improve and partly alter the state of knowledge on Mediterranean groundfish diversity - provide the first description of a 'reference state', with which the temporal changes in diversity patterns patterns throughout the entire northern Mediterranean Sea can be compared in the future.

Acknowledgements. This study was carried out within the framework of the 'Demersal Assemblages' working group of the International MEDITS programme. We thank all participants in the surveys conducted along the coasts of the North Mediterranean Sea within the MEDITS programme. We also thank Michael Paul for linguistic corrections.

\section{LITERATURE CITED}

Abelló P, Abella A, Adamidou A, Jukic-Peladic S, Maiorano P, Spedicato MT (2002) Geographical patterns in abundance and population structure of Nephrops norvegicus and Parapenaeus longirostris (Crustacea: Decapoda) along the Mediterranean coast. Sci Mar 66:125-141

Agresti (1992) Categorical data analysis. Wiley Interscience, New York

Arvanitidis C, Bellan G, Drakopoulos P, Valanavis V, Dounas C, Koukouras A, Eleftheriou A (2002) Seascape biodiversity patterns along the Mediterranean and the Black Sea: lessons from the biogeography of benthic polychaetes. Mar Ecol Prog Ser 244:139-152

Bacescu M (1985) The effects of the geological and physicochemical factors on the distribution of marine plants and animals in the Mediterranean. In: Moraitou-Apostolopoulou M, Kiortis V (eds) Mediterranean marine ecosystems. Plenum Press, New York, p 195-212

Bertrand JA, Gil de Sola L, Papaconstantinou C, Relini G, Souplet A (2002a) The general specifications of the MEDITS surveys. Sci Mar 66:9-17

Bertrand JA, Leonori I, Dremiere PY, Cosimi G (2002b) Depth trajectory and performance of a trawl used for an international bottom trawl survey in the Mediterranean. Sci Mar 66:169-182

Bianchi CN, Mori C (2000) Marine biodiversity of the Mediterranean Sea: situation, problems and prospects for future research. Mar Pollut Bull 40:367-376

Caddy JF (1993) Toward comparative evaluation of human impacts on fishery ecosystems of enclosed and semienclosed seas. Rev Fish Sci 1:57-95

Caddy JF (2000) Marine catchment basin effects versus impacts of fisheries on semi-enclosed seas. ICES J Mar Sci 57:628-640

Colwell RK (2000) EstimateS: statistical estimation of species richness and shared species from samples (software and user's guide), Version 6. Available at http:/viceroy.eeb. uconn.edu/estimates

Colwell RK, Coddington JA (1994) Estimating terrestrial biodiversity through extrapolation. Philos Trans R Soc Lond B 345:101-118

Ellingsen KE (2001) Biodiversity of a continental shelf soft- 
sediment macrobenthos community. Mar Ecol Prog Ser 218:1-15

Ellingsen KE (2002) Soft-sediment benthic biodiversity on the continental shelf in relation to environmental variability. Mar Ecol Prog Ser 232:15-27

Ellingsen KE, Gray JS (2002) Spatial patterns of benthic diversity: Is there a latitudinal gradient along the Norwegian continental shelf? J Anim Ecol 71:373-389

Estrada M (1996) Primary production in the northwestern Mediterranean. Sci Mar 60(Suppl 2):55-64

Gaertner JC, Mazouni N, Sabatier R, Millet B (1999) Spatial structure and habitat associations of demersal assemblages in the Gulf of Lions: a multicompartment approach. Mar Biol 135:199-208

Gaertner JC, Bertrand JA, Samani D, Souplet A (2005a) Spatio-temporal organization of demersal assemblages of the east coast of Corsica (Mediterranean Sea). Vie Milieu 55:81-89

Gaertner JC, Bertrand JA, Gil de Sola L, Durbec JP, Ferrandis E, Souplet A (2005b) Large spatial scale variation of demersal fish assemblages structure on the continental shelf of the NW Mediterranean Sea. Mar Ecol Prog Ser 297:245-257

Garibaldi L, Caddy JF (1998) Biogeographic characterization of Mediterranean and Black Sea faunal provinces using GIS procedures. Ocean Coast Manage 39:211-227

Gaston KJ (2000) Global patterns in biodiversity. Nature 405: 220-227

Golani D, Massuti E, Orsi-Relini L, Quignard JP (2002) Atlas of exotic species in the Mediterranean, Vol 1. Ciesm Publications, Monaco

Gotelli NJ, Colwell RK (2001) Quantifying biodiversity: procedures and pitfalls in the measurement and comparison of species richness. Ecol Lett 4:379-391

Gray S (2002) Species richness of marine soft sediments. Mar Ecol Prog Ser 244:285-297

Harmelin JG, D'Hont JL (1993) Transfers of bryozoan species between the Atlantic Ocean and the Mediterranean Sea via the Straits of Gibraltar. Oceanol Acta 16:63-72

Harrison S, Ross SJ, Lawton JH (1992) Beta diversity on geographic gradients in Britain. J Anim Ecol 61:151-158

Huston MA (1999) Local processes and regional patterns: appropriate scales for understanding variation in the diversity of plants and animals. Oikos 86:393-401

Jukic-Peladic S, Vrgoc N, Krstulovic-Sifner S, Piccinetti C, Piccinetti-Manfrin G, Marano G, Ungaro N (2000) Longterm changes in demersal resources of the Adriatic Sea: comparison between trawl surveys carried out in 1948 and 1998. Fish Res 1106:1-10

Koopmans LH (1981) An introduction to contemporary statistics. Duxbury Press, Belmont, CA

Le Vourch J, Millot C, Castagne N, Le Borgne P, Olry JP (1992) Atlas des fronts thermiques en Méditerranée d'après l'imagerie satellitaire. Mem Inst Oceanogr (Monaco) 16: $1-145$

Loreau M (2000) Are communities saturated? On the relationship between alpha, beta and gamma diversity. Ecol Lett 3:73-76

Maguran AE (2004) Measuring biological diversity. Blackwell Publishing, Oxford

Editorial responsibility: Howard Browman (Associate Editorin-Chief), Storebø, Norway
Mazouni N, Rey-Valette H (2002) The coupling of participative action research and co-management: a contribution towards integrated fishery management. Application to a clam fishery (Thau, France). Ocean Year 16:241-253

McCullagh P, Nelder J (1989) Generalized linear models. Chapman \& Hall, London

Millot C (1999) Circulation in the western Mediterranean Sea. J Mar Syst 20:423-442

Papaconstantinou C (1990) The spreading of Lessepsian fish migrants into the Aegean Sea (Greece). Sci Mar 54: 313-316

Papaconstantinou C, Farrugio H (2000) Fisheries in the Mediterranean. Mediterr Mar Sci 1:5-18

Pérès JM (1967) The Mediterranean benthos. Oceanogr Mar Biol Annu Rev 5:449-533

Pérès JM, Picard JP (1958) Recherches sur les peuplements benthiques de la Méditerranée Nord-Orientale. Ann Inst Oceanogr 34:213-291

Por FD (1989) The legacy of Tethys: an aquatic biogeography of the Levant. Monographae biologicae, Vol 63. Kluwer, Dordrecht

Price ARG (2002) Simultaneous 'hotspots' and 'coldspots' of marine biodiversity and implications for global conservation. Mar Ecol Prog Ser 241:23-27

Purvis A, Hector A (2000) Getting the measure of biodiversity. Nature 405:212-219

Quignard JP, Tomasini JA (2000) Mediterranean fish biodiversity. Biol Mar Mediterr 7:1-66

Relini G, Bertrand J, Zamboni A (eds) (1999) Synthesis of the knowledge on bottom fishery resources in central Mediterranean (Italy and Corsica). Biol Mar Mediterr 6(Suppl 1)

Ricklefs RE (1987) Community diversity: relative roles of local and regional processes. Science 235:167-171

Rivadeneira MM, Fernandez M, Navarrete SA (2002) Latitudinal trends of species diversity in rocky intertidal herbivore assemblages: spatial scale and the relationship between local and regional species richness. Mar Ecol Prog Ser 245:123-131

SAS/STAT (1992) SAS users, Version 8. SAS Institute Inc., Cary, NC

Srivastava DS (1999) Using local-regional richness plots to test for species saturation: pitfalls and potentials. J Anim Ecol 68:1-16

Stergiou KI, Christou ED, Gergopoulos D, Zenetos A, Souvermezoglou C (1997) The Hellenic seas: physics, chemistry, biology and fisheries. Oceanogr Mar Biol Annu Rev 35: $415-538$

Taquet M, Gaertner JC, Bertrand J (1997) Typologie de la flottille chalutière de Sète: formalisation par une méthode de segmentation. Aquat Living Resour 10:137-148

Tortonese E (1985) Distribution and ecology of endemic elements in the Mediterranean fauna (fishes and echinoderms). In: Moraitou-Apostolopoulou M, Kiortis V (eds) Mediterranean marine ecosystems. Plenum Press, New York, p 57-83

Whittaker RH (1972) Evolution and measurement of species diversity. Taxon 21:213-251

Wilson MV, Shmida A (1984) Measuring beta diversity with presence-absence data. J Ecol 72:1055-1064

Submitted: March 30, 2006; Accepted: December 4, 2006

Proofs received from author(s): June 7, 2007 